\title{
FEATURE Comparing cover crop use by horticultural and commodity producers
}

Robert L. Myers and Joseph LaRose

$\mathbf{S}$ tarting in the winter of 201213, the Sustainable Agriculture Research and Education (SARE) program began working with the Conservation Technology Information Center (CTIC) to conduct United States surveys about farmer experiences with cover crops; six surveys have been conducted to date. The American Seed Trade Association (ASTA) also participated in planning and supporting the surveys starting with the 2014-15 survey (CTIC 2015). Surveys were conducted in the winter months and published in spring or summer. They asked about farmer experiences the previous calendar year so were designated by the relevant fall-to-spring period. The first survey addressed the 2012 crop season (a major drought year in most US crop regions) and was labeled the 2012-13 survey (CTIC 2013). The most recent survey was about the 2019 crop (an extremely wet spring in the Midwest) and was identified as the 2019-20 survey (CTIC 2020). There were no surveys on the 2017 and 2018 crop seasons.

Typically, there were more data from the annual surveys than could be thoroughly assessed or summarized in the annual reports, and the main emphasis of the annual reports has been on the experiences of commodity farmers with cover crops. While horticultural producers were usually about $20 \%$ of the population of farmers responding to the survey, this paper is the first attempt to more thoroughly compare the use of cover crops by horticultural producers versus commodity producers.

The first survey (2012-13) was conducted both online and by distributing print copies of the survey at several farmer conferences where cover crop users were a significant part of the audience. All subsequent surveys were conducted only online. In most years, links to the online survey were sent to over 50,000 farmers nationwide. Potential farmers were contacted using subscriber links from Penton
Agriculture Media, CTIC, and SARE. Perhaps most importantly, farmers who had responded to previous SARE/CTIC cover crop surveys were also invited to participate again, and a high percentage of previous respondents filled out the subsequent surveys. This approach led to a good cross section of farmers across the United States, but it should be noted that survey respondents were self-selecting and not a truly random survey of the farmer population.

After the first survey question confirmed that respondents were farmers, the second question separated users and nonusers of cover crops. The total number of farmers filling out the survey varied by year, with the lowest number being 759 for the 2012-13 survey, the next lowest being 1,172 for the 2019-20 survey, and typically about 2,000 respondents for the other four surveys covering the 2013-16 seasons (CTIC 2014, 2015, 2016, 2017). The survey represents a cross section of farmers from different size farms, including smaller horticulture operations. Survey respondents came from nearly every state, but major agricultural states in the Corn Belt had the highest number of respondents.

In most years, at least $80 \%$ of the participants identified as commodity crop farmers. However, hundreds of responses still came from horticultural producers, who made up $19 \%$ of participants in the 2014-15 and 2015-16 surveys, 20\% for $2016-17$, and $19 \%$ for $2019-20$. The first two surveys (2012-13 and 2013-14) did not ask farmers if they were primarily commodity or horticultural producers, but it is believed some horticultural users responded based on farm sizes reported.

In the 2019-20 survey, the 235 horticulture users of cover crops responding to the survey were asked to report which types of horticultural crops represented at least $10 \%$ of their farmer income. Vegetables were by far the most common response, with about equal responses for vegetable

Received December 19, 2021.

root crops (e.g., carrots [Daucus carota], potatoes [Solanum tuberosum], radishes [Raphanus sativus]), cucurbits (Cucurbita spp.; such as pumpkins, zucchini, squash, other gourds), brassicas (lettuce [Lactuca sativa], spinach [Spinacia oleracea], kale and broccoli [Brassica oleracea], etc.), and other vegetable crops. After vegetables, a much smaller number reported producing annual fruits (e.g., strawberries [Fragaria $\times$ ananassa], melons [Cucurbitaceae spp.], etc.) or perennial fruits other than grapes (Vitus spp.; tree fruits, bush berries, brambles, etc.). An even smaller number responded that they derived significant income from grapes or nut crops.

\section{ADOPTION OF COVER CROPS}

The type of farming operation, commodity or horticultural, is a useful way to divide and examine cover crop users because it generally encompasses differences in cropping systems and farm size that affect cover crop practices. Horticulture and commodity farmers likely have a different history and current relationship with cover cropping. Cover crops maintained their role in horticultural operations after the introduction of industrial agriculture methods to a greater degree than in commodity style agriculture, and this was reflected in the survey data. In the 2017 survey, nearly $25 \%$ of horticulture cover crop users had 10 or more years of experience, while only $17 \%$ of commodity producers had that much cover crop experience (figure 1).

In terms of cover crop land area, the average number of acres (hectares) of cover crops reported planted by farmers who identified as primarily horticultural producers was about $100 \mathrm{ac}$ (40 ha) in the

Robert L. Myers is regional director of extension programs for the North Central Region Sustainable Agriculture Research and Education Program and also serves as director of the Center for Regenerative Agriculture at University of Missouri, Columbia, Missouri. Joseph LaRose is a natural resource specialist with the Department of Defense, Quantico, Virginia, and was formerly an extension specialist with University of Missouri. 


\section{Figure 1}

(a) Years of cover crop experience and (b) percentage of farm in cover crops among horticultural and commodity producers.

(a)

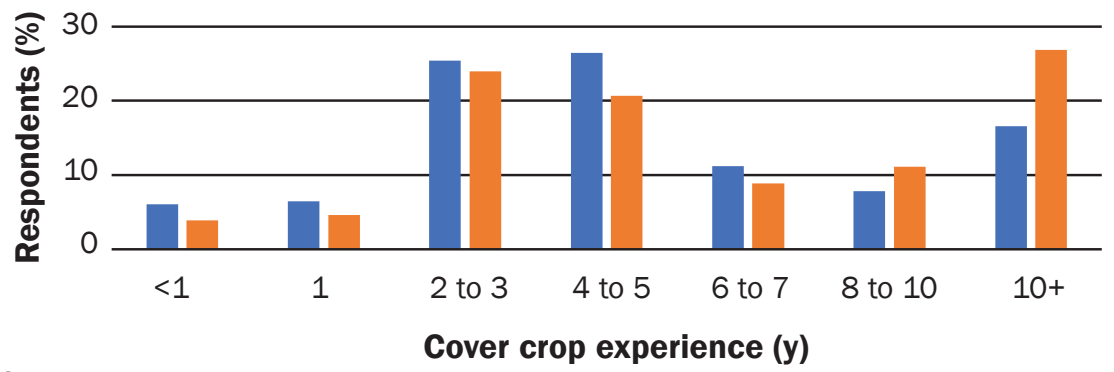

(b)

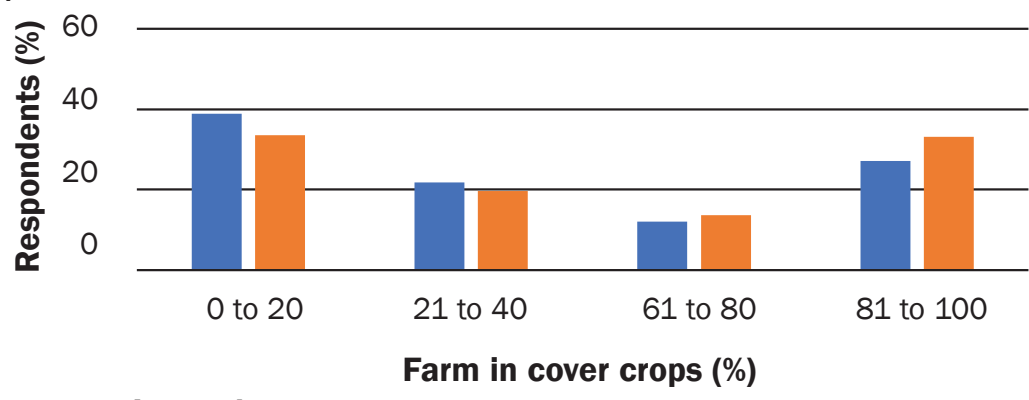

Legend

Commodity

\section{THE PREVALENCE OF MIXES BY FARMER TYPE}

Cover crop mixes are popular among both horticultural and commodity producers, especially as they gain experience. However, the 2015-16 survey showed a higher percentage of horticultural producers $(69 \%)$ using cover crop mixes compared to commodity producers (56\%); almost identical response percentages were obtained on this question in the 2016-17 survey.

By the time farmers had four or more years of experience with cover crops, over $80 \%$ were using mixes. This may reflect a growing comfort with diversity. Farmers with more cover crop experience were also more likely to have increased the diversity in their mixes.

The extensive use of cover crop mixes has implications for future cover crop research. Most research has focused on single species of cover crops, in particular cereal rye, partly for the sake of simplicity and experimental control. But while academia has focused on isolating the effects of single cover crop species, farmers are embracing mixes. Thus, it would be helpful to farmers for future research to include more use of cover crop mixes.

\section{SEEDING METHODS} few years. Not surprisingly, the much larger commodity farm operations were planting a higher acreage of cover crops per farm, even though the percentage of the farm planted to cover crops was lower than on the horticulture operations. The per farm average was closer to 400 ac (162 ha) of cover crops and had risen steadily over the previous few years.

Both horticultural producers and commodity producers responding to the survey had a similar distribution of responses in terms of the percentage of their farm being cover cropped. Slightly more horticultural producers were $100 \%$ cover cropped. From the 2017 survey, 33\% of horticultural growers reported all of their farm was planted with cover crops, while $27 \%$ of commodity farmers said the same.

\section{COVER CROP SPECIES USED}

Horticultural and commodity producers also differ in which cover crops they employ. While cereal rye (Secale cereale) is by far the most common cover crop used by commodity farmers (figure 2), there is a greater balance of various cover crop species used by horticultural producers. For horticulture users, oats (Avena sativa) and buckwheat (Fagopyrum esculentum) are more popular than cereal rye, with various legumes close behind in popularity. Using buckwheat as a cover crop is somewhat uncommon for commodity farmers, but some do use buckwheat in summer cover crop mixes.

These differences in cover crop species selection between horticultural and commodity farmers and other management differences should be taken into account for education programs on cover crops. Crop advisors or extension professionals looking for information on certain cover crops such as buckwheat or hairy vetch (Vicia villosa) could turn to horticultural producers for assistance. Likewise, some of the large-scale no-till and planting green innovations that have come from commodity farming could have applications in horticulture. crops with a grain drill $(38 \%)$ or had them aerially applied (23\%). Another $14 \%$ of seeding was done by broadcasting with light seed incorporation, while $11 \%$ was broadcasting with a fertilizer spreader or other method that simply left the cover crop seed on the surface. High clearance broadcast spreaders were used in $7 \%$ of situations, while $4 \%$ of seeding was reported using precision planters (like corn [Zea mays]/ soybean [Glycine $\max ]$ row planters). The remaining 3\% was done by other methods. Farmers responding to this question were allowed to select more than one response among several seeding methods.

By contrast, horticultural users at that time were primarily seeding cover crops by broadcasting with light seed 


\section{Figure 2}

Percentage of cover crop planted by individual species for commodity producers compared to horticultural producers: (a) 2015 cover crop use by species and (b) 2016 cover crop use by species.

(a)

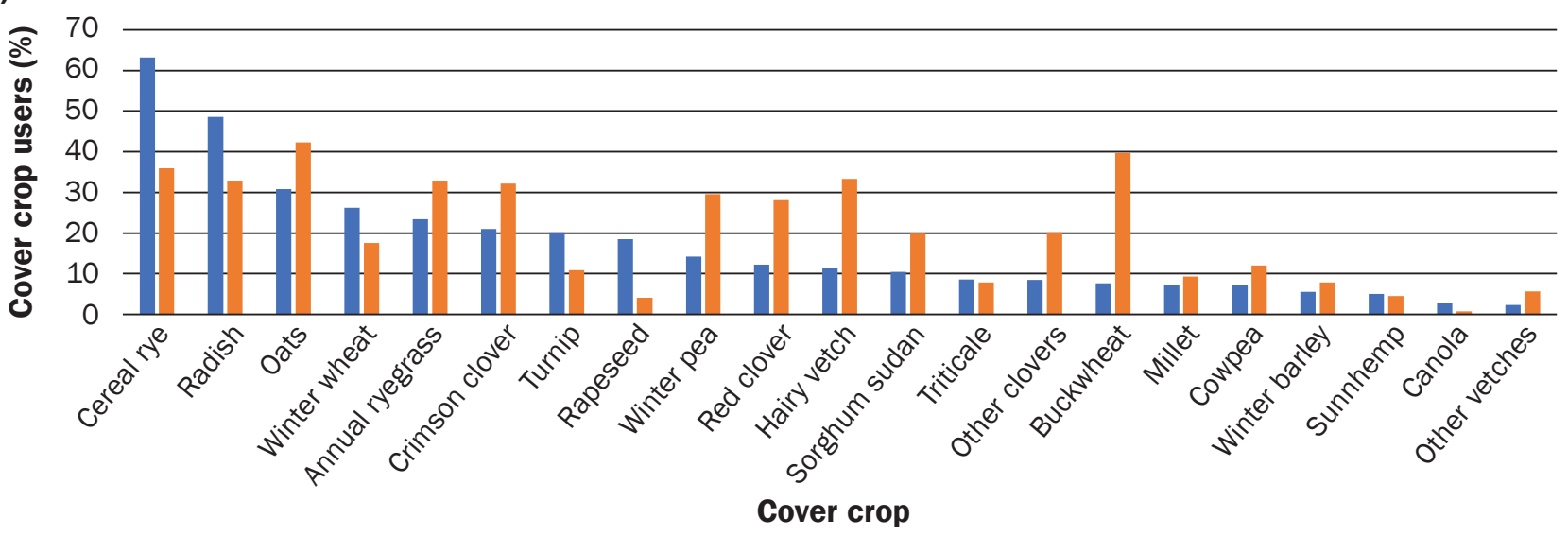

(b)

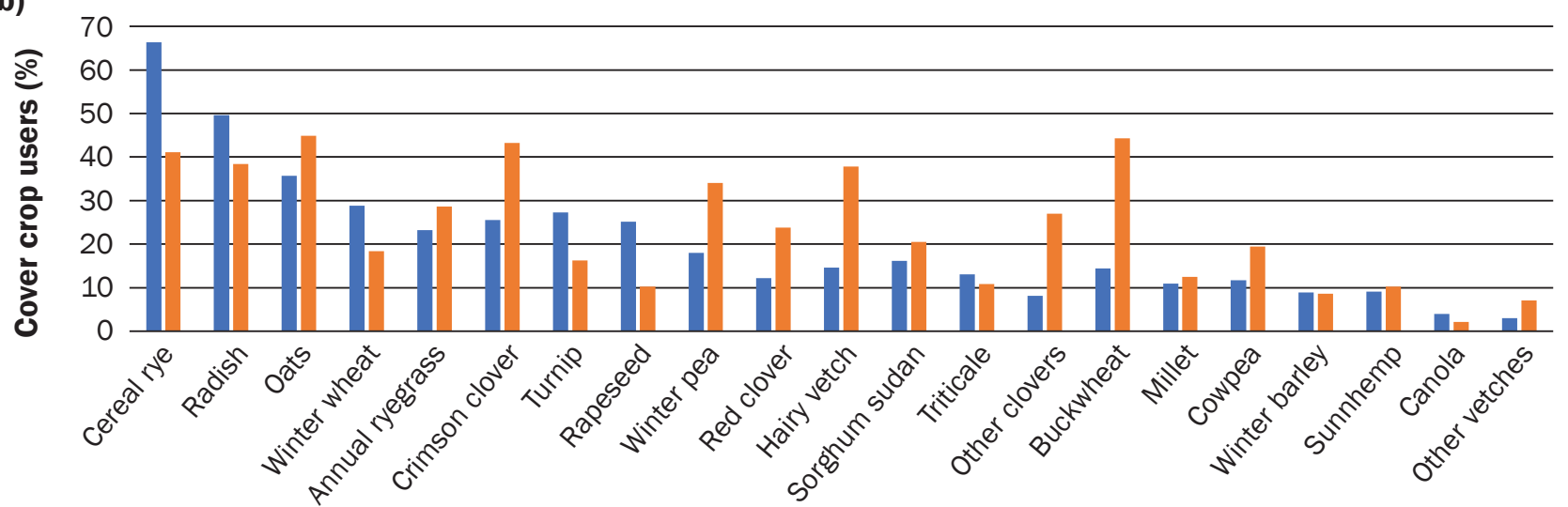

\section{Legend}

Commodity

Cover crop

Horticulture

incorporation (45\%), while $18 \%$ were broadcasting with a fertilizer spreader or other method that simply left the cover crop seed on the surface. Another 9\% seeded with a high clearance broadcasting device. Drills were used much less by horticultural farmers, only $16 \%$, probably reflecting the fact that most horticulture operations don't have a grain drill; only $2 \%$ of horticultural producers used a precision planter for cover crops. Aerial seeding was also relatively rare in horticultural operations at $4 \%$, reflecting the smaller size of most horticulture farms; it wouldn't make sense to hire an airplane for smaller patches. The remaining 6\% was done by other methods.

\section{TILLAGE USE WITH COVER CROPS}

Horticulturalists may on average have more cover crop experience than commodity farmers, but commodity farmers reported being able to farm with less soil disturbance (figure 3). Respondents were asked to identify the primary type of tillage employed on their farm. The results show an obvious difference in the use of conventional tillage and no-till. No-till was almost three times more common among commodity cover crop users, although many horticultural farmers did make use of rotational no-till (which refers to using no-till before planting some cash crops and tillage before planting other cash crops in the rotation).
Although horticultural producers using cover crops make more use of tillage on average than commodity producers using cover crops, there was a positive connection seen between cover crop adoption and tillage impacts in the 2019-20 survey. Of the horticultural producers adopting cover crops, $56.8 \%$ reported reducing tillage use either slightly or significantly (about equal portions in each category). By contrast, only $2.2 \%$ significantly increased tillage and $5.3 \%$ slightly increased tillage following cover crop adoption.

\section{TERMINATION OF COVER CROPS}

The 2014-15 survey was the first to compare how commodity producers versus horticultural producers terminate their 


\section{Figure 3}

General tillage approach for commodity producers versus horticultural producers.

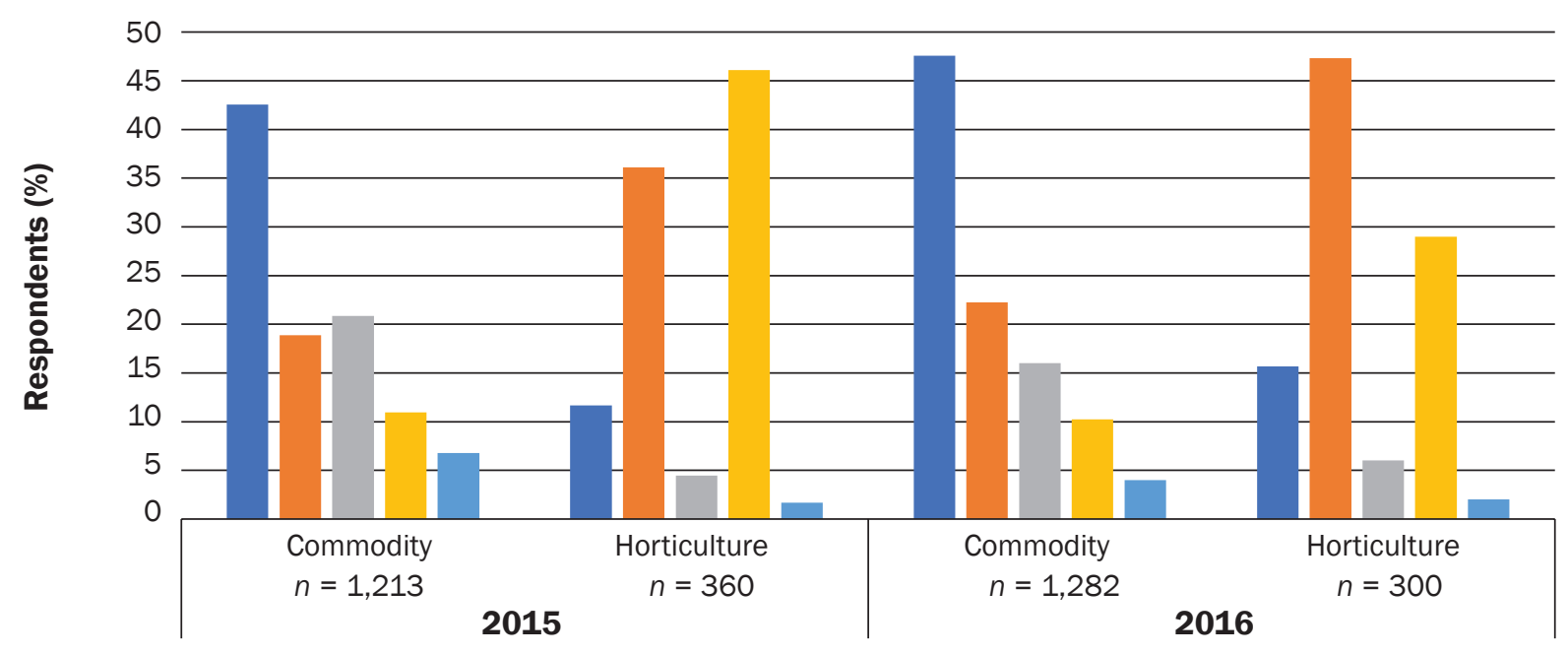

Legend

No-till $\quad$ Rotational no-till $\square$ Reduced tillage $\square$ Conventional tillage $\square$ Vertical tillage

cover crops. At that time, $59 \%$ of commodity producers were primarily using herbicides to terminate cover crops, versus only $4 \%$ of horticultural producers. By contrast, horticultural producers were much more likely to use tillage to terminate cover crops, with $49 \%$ selecting that option versus $10 \%$ of commodity farmers. Mowing for termination was also much more common among horticultural producers with $19 \%$ of them terminating that way versus $4 \%$ of commodity producers. Both types of farmers were about equally likely to rely primarily on cover crops that winter kill (24\% for commodity producers and $20 \%$ of horticultural producers). Relatively few producers were primarily relying on roller-crimpers for termination, with $4 \%$ of horticulture and only $1 \%$ of commodity operations using that method; however, an additional few percent of each farmer type did use roller-crimpers for a portion of their cover crop termination.

The 2019-20 survey gave an updated look at how horticultural producers are terminating cover crops (figure 4) but did not ask that question of commodity producers. The biggest difference from the 2014-15 survey was that more of the horticultural respondents reported using herbicides for termination (23.7\%); this difference probably reflects that some hor- ticultural respondents in the most recent survey have both row crops and vegetables; they were likely spraying cover crops for termination in their larger row crop fields. Other common cover crop termination methods by horticultural users were tillage $(25.6 \%)$ or mowing $(23.7 \%)$. Another $16.3 \%$ were primarily using a cover crop that is killed by winter conditions, with no additional termination steps needed.

\section{Figure 4}

Primary or most common termination methods for cover crops reported by horticultural producers.

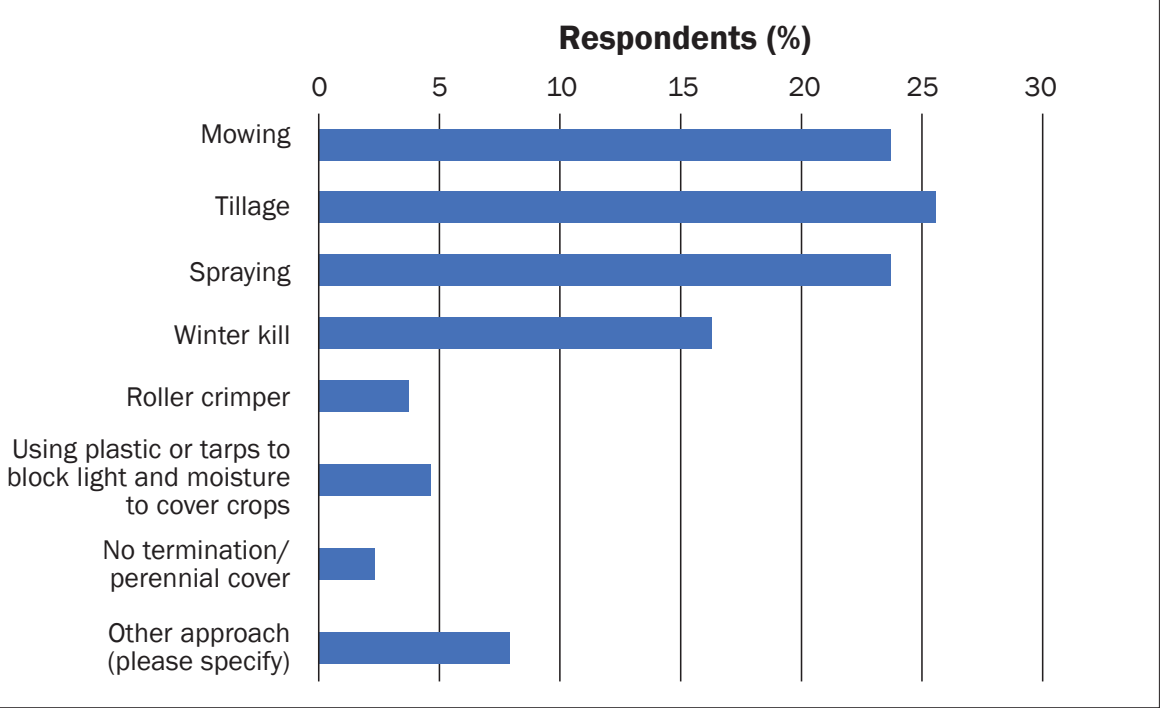

Not surprisingly, mowing was about six times more likely to be used as a mechanical means of termination compared to a roller crimper (a primary termination tool for only 4\%); most horticultural farmers already have mowing equipment, but few have roller crimpers.

One of the newest approaches for cover crop termination on small horticulture operations is the use of plastic sheets or 
tarps to kill the cover crop (4.7\%). While not practical on a large scale, such smothering methods effectively allow a plot to benefit from a cover crop without requiring tillage, mechanical equipment, or sprays, and can leave the ground in good condition for planting. The survey included responses from a small number of farmers who were using perennial covers that don't need termination, most likely where perennial fruits or nuts are being grown (eg., vineyards, orchards, or berry production).

\section{PROFIT FROM USE OF COVER CROPS}

One of the more common questions about cover crops is how they impact the profitability of farms. For commodity producers, who frequently have low or negligible profit margins per acre, minimizing any extraneous cost is a major objective. Perceptions about potential added cost from cover crops likely hold back some commodity farmers from using them, despite the fact that an increasing number of studies are showing improved profit over time from cover cropping.

For horticultural producers, there has been an assumption that the much higher production costs per acre for fruits and vegetables make the US $\$ 20$ to US $\$ 30$ $\mathrm{ac}^{-1}$ (US $\$ 49 \mathrm{ha}^{-1}$ to US $\left.\$ 74 \mathrm{ha}^{-1}\right)$ seed cost of cover crops a much more minor consideration, especially if that horticulture operation has a modest number of acres. Still, horticultural producers watch their costs just as much as those in the commodity business.

Through the 2019-20 survey, some of the first data on cover crop profitability for horticultural producers were obtained. Taking into account the large number of crops used in many horticulture operations, and the widely varying costs and income associated with each horticultural crop, it was determined that percentage impact on profitability was a more useful way to ask about profit impacts rather than dollars per acre.

While 38\% said that cover crops had no significant impact on their net profit, over half the farmers reported either a minor $(23.4 \%)$ or moderate $(34.8 \%)$ increase in net profit. By contrast, only 3.8\% of respondents reported a minor decrease in net profit (presumably from the cost of cover crop seed) while none of the farmers reported having moderate decreases in net profit. This generally favorably assessment of cover crop profitability impacts, with over half seeing a positive benefit and most of the rest indicating a neutral impact, helps illustrate why cover crops are popular with horticultural producers.

In the 2019-20 survey, corn and soybean yield information was gathered as in past surveys, with just those farmers having comparable fields both with and without cover crops asked to report yields. Of those reporting yields, average yield increase following cover crops was $5.0 \%$ for soybeans and $2.0 \%$ for corn, which would provide a small boost to financial returns.

Not all cost factors were surveyed, but the 2019-20 survey was the first to ask commodity farmers more specifically about their experiences with fertilizer and herbicide costs where they had been using cover crops for at least three years (that period was chosen to reflect potential impact of improved soil health). Of the farmers providing economic data, $49.0 \%$ reported having fertilizer savings for corn and $40.8 \%$ for soybeans. For herbicides, $38.7 \%$ reported savings for corn and $41.1 \%$ for soybeans. Some farmers kept their herbicide inputs/costs the same but reported improved weed control following cover crops, with $39.8 \%$ saying they observed better weed control for corn and $39.2 \%$ for soybeans.

A major economic analysis was done in 2019 based on the first five years of SARE/ CTIC survey data (Myers et al. 2019). That study determined that on average it took three years for cover crop use to break even financially on corn and soybean fields. There was a net cost for using cover crops in the first two years but starting with the fourth year of cover crop use, a net profit was calculated for subsequent years. The report further included evaluation of seven specific management scenarios where cover crops might be employed, such as dealing with soil compaction, herbicide-resistant weeds, low fertility soils, grazing systems, and helping ease transition to no-till. For most of the management scenarios evaluated, cover crop net returns could occur faster when being employed to achieve specific field needs, often being profitable within two years and sometimes within one year; grazing cover crops was one of the fastest ways to make them provide a profitable net return. Financial incentive payments for cover crops were also noted as being a way to make cover crop use immediately affordable.

A number of other studies have looked at economics of cover crops specifically or in combination with no-till. One of the largest recent efforts was a detailed case study analysis of 100 farms from nine states in the Midwest, Great Plains, and MidSouth, with most of the farms using both no-till and cover crops (SHI 2021). They found corn had a net profit increase averaging US $\$ 51.60 \mathrm{bu}^{-1}$ (US $\left.\$ 2.03 \mathrm{~kg}^{-1}\right)$, and soybeans had a net profit increase averaging US $\$ 44.89 \mathrm{bu}^{-1}$ (US $\left.\$ 1.65 \mathrm{~kg}^{-1}\right)$, based on a combination of no-till and/or cover crop use (not all farms had cover crops).

A smaller set of detailed case studies was done in Iowa, Illinois, and Missouri by Datu Research in cooperation with the National Association of Conservation Districts (Datu Research 2017). Of the three farms with cover crops, the Iowa farm had an average net loss of US $\$ 22 \mathrm{ac}^{-1}$ (US\$54 ha $\mathrm{h}^{-1}$ ) from cover crops in their first three years of use, a Missouri farm had an average net profit of US $\$ 16 \mathrm{ac}^{-1}$ (US $\$ 40 \mathrm{ha}^{-1}$ ) over their first four years of cover cropping, and an Illinois farm had an average net profit of US $\$ 19$ $\mathrm{ac}^{-1}\left(\mathrm{US} \$ 47 \mathrm{ha}^{-1}\right)$ over their first five years of use, with a positive net of US\$76 ac $\left(\mathrm{US} \$ 188 \mathrm{ha}^{-1}\right)$ in their fourth year of use.

\section{MOTIVATIONS}

Several of the surveys asked all cover crop users about cover crop benefits, but the 2019-20 survey was the first to specifically ask horticultural producers about their motivations for adopting cover crops. Farmers were allowed to select more than one response from among eight possible options. As with commodity producers, the most commonly cited motivation for cover crop use was improving soil health (94\%). However, unlike data from commodity producers in past surveys (who usually rate soil erosion second), horticultural producers rated weed management as the second biggest motivation (81\%). Third was reducing erosion (71\%), and fourth was improved water (rainfall) infil- 


\section{Figure 5}

Primary reasons that horticultural producers use cover crops.

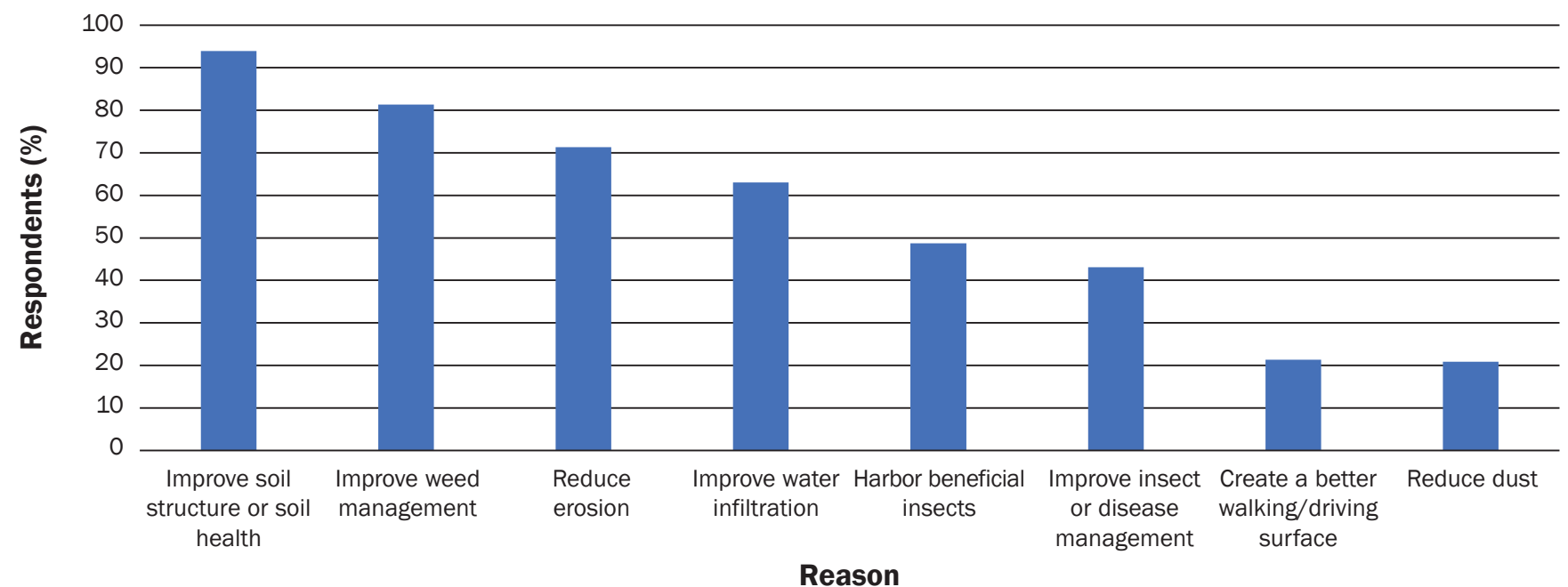

Reason

tration (63\%). A little less than half the horticultural producers indicated pest control and harboring beneficial insects as motivating factors, while less than a quarter cited having a better driving/walking surface or reduced dust as being reasons for using cover crops. Allowed to also enter comments about other cover crop motivations, some farmers cited being able to avoid using plastic weed barriers.

Commodity farmer motivations with cover crops and perceptions of benefits have been queried in a number of ways over the various cover crop surveys, particularly in the first four years of the surveys. The most recent survey to evaluate perceptions of cover crop benefits just by commodity farmers was the 2014-15 survey. Increased soil health ranked as the top perceived benefit, followed in order by improved soil organic matter, reduced erosion, control of weeds, providing a nitrogen $(\mathrm{N})$ source, scavenging nutrients, increasing yields, providing fibrous rooting, economic returns, and finally deep tap rooting (which few selected). Other SARE/CTIC surveys showed similar patterns, with improved soil health and reduced soil erosion consistently ranking near the top.

A recent study (Lo et al. 2021) focusing on Tennessee row crop producers found out of nine potential benefits, farmers ranked cover crop benefits as most likely to least likely for the following factors, in order: reduce erosion, improve soil quality/health, improve water quality, retain soil moisture, control weeds, increase planting difficulty, increase profit, increase yield, and reduce yield variability.

\section{SUMMARY}

Although horticultural and commodity producers have some notable differences in their cover crop uses, including species used, termination practices, and types of tillage, both have found cover crops to provide many benefits, including improved profits over time. Both cite reduced soil erosion, improved weed control, better soil fertility, and increased soil health.

Cover crops have played a significant role on horticultural farms for a longer period of recent decades than commodity farms, but both types of farmers are increasing cover crop use and finding more ways to efficiently fit cover cropping into their operations. While horticultural producers do use tillage as one of several common methods of cover crop termination, over half reported that they reduced their use of tillage after adopting cover crops. Both types of farmers report being able to cut back somewhat on input costs and improve their profitability with cover crops.

Future research should take into account some of the unique differences for cover crop use among types of farmers, includ- ing tests with a much wider number of cover crops than just cereal rye, and especially doing more research on cover crop mixes. Further progress with cover crop use and adoption can be expected, driven by ongoing farmer experiences, new cover crop management technology and varieties, public and private sector incentives, education efforts, and research insights.

\section{ACKNOWLEDGEMENTS}

The authors wish to thank the following individuals for their contributions to planning, distributing, and/or analyzing various years of the National Cover Crop Farmer Surveys: from CTIC, Steve Werblow, Chad Watts, Karen Scanlon, Mike Smith, and Sue Tull; from the American Seed Trade Association, Jane DeMarchi and members of the Cover Crop Working Group; from Purdue University, Linda Prokopy and the Wallace Tyner research team; from MARC-IV, Alan Weber; from SARE, Andy Zieminski and Sean McGovern; and from Penton Farm Media, Kurt Lawton (organizations listed are for individuals at the time of their contributions).

\section{REFERENCES}

CTIC (Conservation Technology Information Center). 2013. Report of the 2012-13 National Cover Crop Survey. West Lafayette, IN: Conservation Technology Information Center and the Sustainable Agriculture Research and Education Program.

CTIC. 2014. Report of the 2013-14 National Cover Crop Survey. West Lafayette, IN: 
Conservation Technology Information Center and the Sustainable Agriculture Research and Education Program.

CTIC. 2015. Report of the 2014-15 National Cover Crop Survey. West Lafayette, IN: Conservation Technology Information Center and the Sustainable Agriculture Research and Education Program.

CTIC. 2016. Report of the 2015-16 National Cover Crop Survey. West Lafayette, IN: Conservation Technology Information Center and the Sustainable Agriculture Research and Education Program.

CTIC. 2017. Report of the 2016-17 National Cover Crop Survey. West Lafayette, IN: Conservation Technology Information Center and the Sustainable Agriculture Research and Education Program.

CTIC. 2020. Report of the 2019-20 National Cover Crop Survey. West Lafayette, IN: Conservation Technology Information Center and the Sustainable Agriculture Research and Education Program.

Datu Research. 2017. The Economics of Cover Crops and No-Till. Research report. Durham, NC: Datu Research.

Lo, Y.-L., C.D. Clark, C.N. Boyer, D.M. Lambert, B.C. English, and F.R. Walker. 2021. Middle and West Tennessee producer perceptions of no-till and cover crops. Journal of Soil and Water Conservation 76(5):392-402. https://doi. org/10.2489/jswc.2021.02169.

Myers, R.L., J.A. Weber, and S.R. Tellatin. 2019. Cover Crop Economics. Technical Bulletin. Washington, DC: USDA Sustainable Agriculture Research and Education.

SHI (Soil Health Institute). 2021. Economics of Soil Health Systems. Research report. Morrisville, NC: Soil Health Institute. 